American Journal of Applied Sciences 7 (8): 1083-1086, 2010

ISSN 1546-9239

(C) 2010 Science Publications

\title{
Enzymatic Synthesis of Palm Alkyl Ester Using Dialkyl Carbonate as an Alkyl Donors
}

\author{
Roila Awang and Choo Yuen May \\ Malaysian Palm Oil Board, Engineering and Processing Division, \\ No. 6, Persiaran Institute, Bandar Baru Bangi, \\ 43000 Kajang, Selangor, Malaysia
}

\begin{abstract}
Problem statement: Though efficient in terms of reaction yield and time, the chemical approach to synthesizing alkyl ester has drawback such as difficulties in the recovery of glycerol and the need for removal of salt residue. On the other hand, biocatalyst allow for synthesis of specific alkyl esters and easy recovery of glycerol. However, the solvent-free alcoholysis, does not give high conversion. The same problem was also found when ethyl or methyl acetate was used as acyl acceptors. Approach: Lipase catalyzed transesterification of oil and dialkyl carbonate was predicted to give higher conversion in solvent free reaction system. Results: Alkyl esters were synthesized enzymatically to overcome the problems associated with chemical processes. In this study, dialkyl carbonates were used as an alkyl donor for the production of alkyl ester. Nine commercial lipases were tested for their suitability for the reaction system. Among the lipase tested, Novozym 435 was chosen for optimization study because of their higher activity. In a solvent-free reaction system, the ester formation using dialkyl carbonate was 6 times higher than using ethanol and methanol. The effect of various reaction parameters such as temperature, amount of enzyme, organic solvent and structure of substrates were studied to determine optimal condition. The optimal conditions of ester formation were reaction temperature at $60^{\circ} \mathrm{C}$, reaction time at $8 \mathrm{~h}$, enzyme amount of $10 \%(\mathrm{w} / \mathrm{w}$ of oil) and $0.2 \% \mathrm{wt}$ added water. Conclusion: Solvent-free lipase catalyzed transesterification of palm kernel oil and dialkyl carbonates gave higher conversion of ester compared to the reaction using short chain alcohol as an alkyl donors.
\end{abstract}

Key words: Transesterification, palm kernel oil, dialkyl carbonates

\section{INTRODUCTION}

Nowadays, dialkyl carbonate has been attracting wide attention as an environmentally benign chemical raw material (Ono, 1997). It can be used as alkylating and alkylcarbonylating agents in place of dialkyl sulphate, alkyl halides and phosgene. Dialkyl carbonates generate carbon dioxide and alcohol as byproduct during alkylation (Shaikh and Sivaran, 1996). The use of dialkyl carbonates as alkylating agent has been thoroughly studied using various catalysts and conditions and appears to be the reagent of choice for the methylation of phenols (Gryglewicz et al., 2003). Although interest in organic synthesis using dialkyl carbonate has increased, but not much information on enzymatic synthesis of alkyl esters with dialkyl carbonates has been reported.

Transesterification of fatty acids with dialkyl carbonates to produce ester has been reported by
Pioch et al. (1991). Lipase-catalyzed transesterification of vegetable oil with dialkyl carbonates is predicted to give a higher conversion than the conventional methods. This reaction system is not an equilibrium reaction, due to decomposition of the intermediate compound to carbon dioxide and alcohol (Warwel et al., 1999a; 1999b). However, the source of lipase and some key aspects of lipasecatalyzed ester synthesis with dialkyl carbonates such as the role of water, temperature and pressure conditions and substrate effect on the ester formation have not been examined.

\section{MATERIALS AND METHODS}

Materials: Palm kernel oil was purchased from Malaysia's Oleochemical companies. Lipozyme IM and Novozym 435 (N4) were obtained from Novozyme A/S, while Candida B Silica (CBS) was donated by 
Novozyme A/S. Lipase powders from Mucor Javanicus L. (MJL), Mucor Miehei (MML), Candida Cylindracea L. (CCL) and Candida Rugosa (CRL) were from Fluka (Switzerland) and Carica Papaya L. (CPL) was from Sigma.

Esterification reaction: Screening experiments with lipases were conducted at $10 \%$ lipase by weight of triglycerides, with isohexane or dialkyl carbonate as a solvent. A typical reaction was run as follows: to a stoppered $100 \mathrm{~mL}$ Erlenmeyer flask, containing palm kernel oil $(2.01 \mathrm{~g}, 2.86 \mathrm{mmol})$ in solvent (isohexane or dialkyl carbonate) $(8 \mathrm{~mL})$, was added 3 mole equivalents of the dialkyl carbonate and the appropriate amount of lipase. The reaction mixture was shaken at $150 \mathrm{rpm}$ for $8 \mathrm{~h}$ at $45^{\circ} \mathrm{C}$. Progress of the reaction was followed by gas chromatographic analysis. Other reactions were run in a similar manner but without solvent.

Analysis of product: A portion of reaction product (10 $\mathrm{mg})$ was dissolved on dichloromethane $(100 \mu \mathrm{L})$ and N,O-Bis Trimethylsilyl Flouroacetamide (BSTFA) $(200 \mu \mathrm{L})$ was added. The mixture was heated on a water bath for $15 \mathrm{~min}$. After cooling the mixture to room temperature, hexane was added. An aliquot of the mixture was separated by lipid class (alkyl ester, monoglyceride, diglyceride and triglycerides) according to carbon number by gas chromatography as follows: a $12 \mathrm{~m}$ long, a non-polar High Temperature capillary column (HT5), $0.22 \mathrm{~mm}$ i.d., $0.1 \mu \mathrm{m}$ film thickness was used. The silylated samples were injected directly oncolumn into a HP6890 gas chromatograph. The initial oven temperature was $70^{\circ} \mathrm{C}$, followed by a temperature program of $20^{\circ} \mathrm{C} \mathrm{min}^{-1}$ to a final temperature of $350^{\circ} \mathrm{C}$ which was held for $4 \mathrm{~min}$. Heptadecanoic methyl ester was used as internal standard.

\section{RESULTS AND DISCUSSION}

Screening of lipase: Commercial lipases are sold on the basis of their hydrolytic activity and there is no guarantee with regards to their esterification activity. Therefore, it is necessary to screen suitable enzyme for their desired synthetic activity under various processing conditions.

Preliminary experiments were carried out with nine commercial lipases for alkyl ester synthesis to identify the most suitable lipases enzymes for subsequence esterification reaction. The lipase from Candida sp. was found to be the most effective lipase for this reaction system (Fig. 1). Therefore this lipase is chosen for optimization study. The results also indicated that the presence of hydrocarbon solvent did not improve ester formation under tested conditions.

Effects of alkyl sources on the esters formation: The type of alkyl source plays an important role in the reaction kinetic when enzymes are used as catalyst. As shown in Fig. 2, the rate of ester formation using dimethyl and diethyl carbonate was 6-7 times higher than that obtained with methanol and ethanol. This is due to the solubility of dialkyl carbonate in oil is higher than alcohols. In addition, the reaction between dialkyl carbonates and triglycerides is not an equilibrium reaction, where the intermediate compound is immediately decomposes to carbon dioxide and alcohol.

Effect of lipase concentration: From an applied point of view, the substrate concentration should be as high as possible to obtain a higher degree of yield. Simultaneously, the amount of enzyme used should be as low as necessary to obtain the desired result.

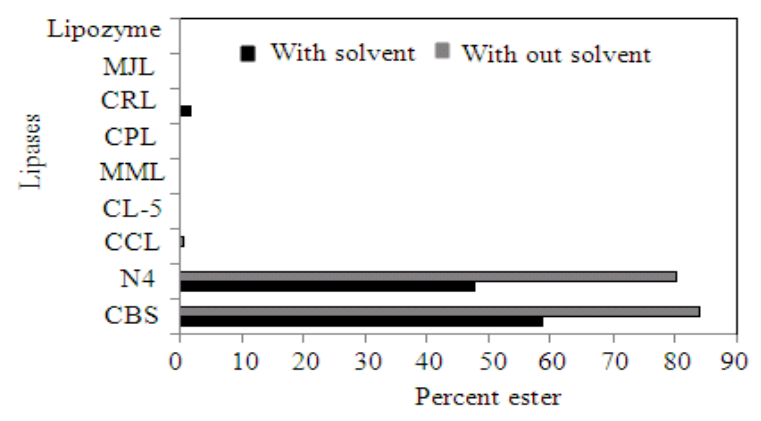

Fig. 1: Screening of lipase for transesterification of palm kernel oil and dialkyl carbonates. Temperature, $60^{\circ} \mathrm{C}$; time, $8 \mathrm{~h}$, mole ratio (oil: Alcohol), 1:3; catalyst, 10\% wt

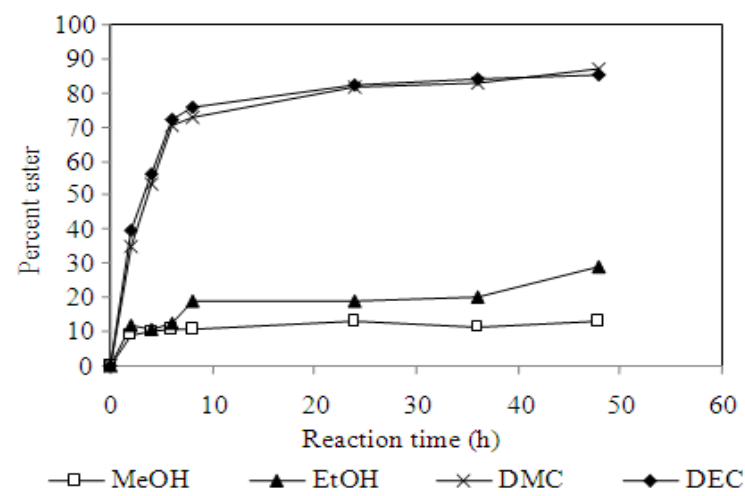

Fig. 2: Effect of alkyl source on the ester formation. Temperature, $60^{\circ} \mathrm{C}$; catalyst, $10 \% \mathrm{wt}$ 


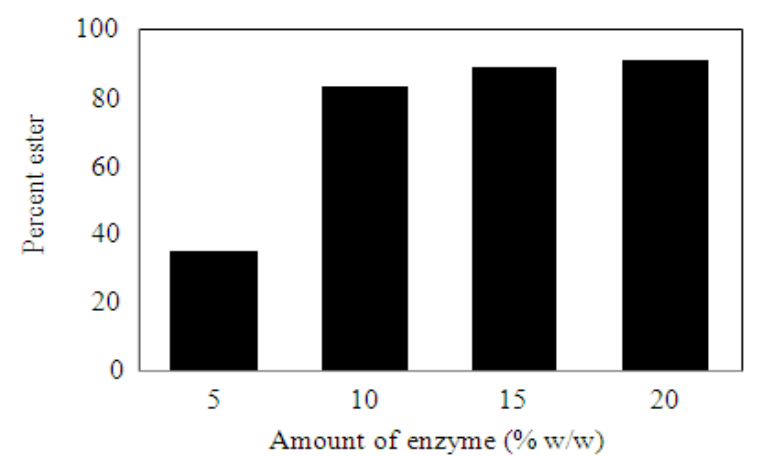

Fig. 3: Effect of lipase concentration on the transesterification of PKO and DMC. Temperature, $60^{\circ} \mathrm{C}$; Time, $24 \mathrm{~h}$

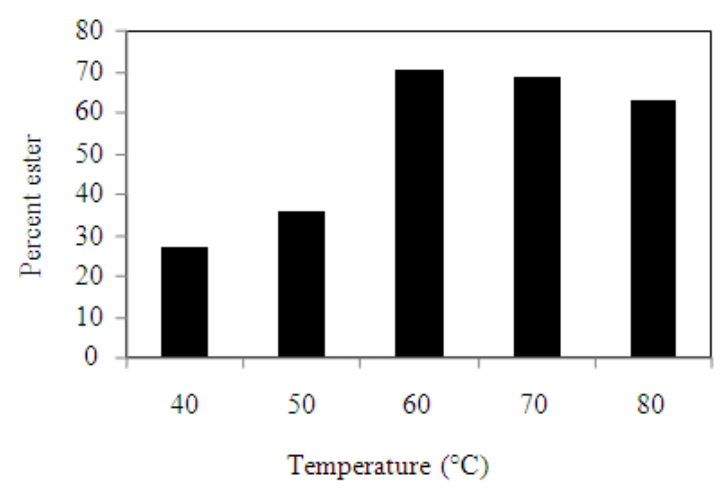

Fig. 4: Effects of reaction temperature on the transesterification of PKO and DMC. Time, $8 \mathrm{~h}$; catalyst, $10 \% \mathrm{wt}$

In terms of production cost, the impact of the amount of lipase is crucial. Figure 3 shows the percent ester increases as the amount of enzyme is increased. However, with the amount enzyme above $10 \%\left(\mathrm{w} \mathrm{w}^{-1}\right)$, there were relatively small increases in percent conversion. These results indicate that the excess enzyme used did not contribute to the increase of the percent ester. In this case, substrate limiting may be the reason, therefore $10 \%$ of enzyme was sufficient to catalyze the esterification reaction between palm kernel oil and dialkyl carbonate.

Effect of reaction temperature: Changes in the reaction temperature can affect the activity and stability of the enzymes and thus the rate of reaction. The influence of temperature range of $40-80^{\circ} \mathrm{C}$ was studied (Fig. 4). Higher conversion was obtained when the reaction was carried out at $60^{\circ} \mathrm{C}$. Beyond this temperature the percent ester was slightly decreased. This may be done to the deactivation of the enzyme (Athawale et al., 2003).

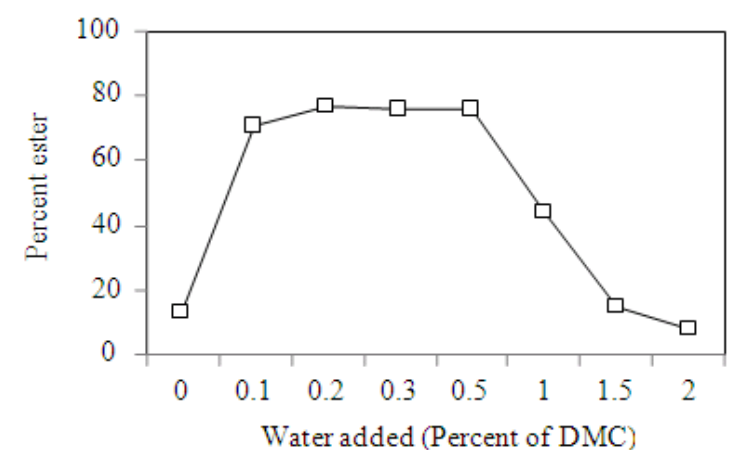

Fig. 5: Effect of water content on the transesterification of PKO and DMC. Temperature, $60^{\circ} \mathrm{C}$; time, $8 \mathrm{~h}$; catalyst, $10 \% \mathrm{wt}$

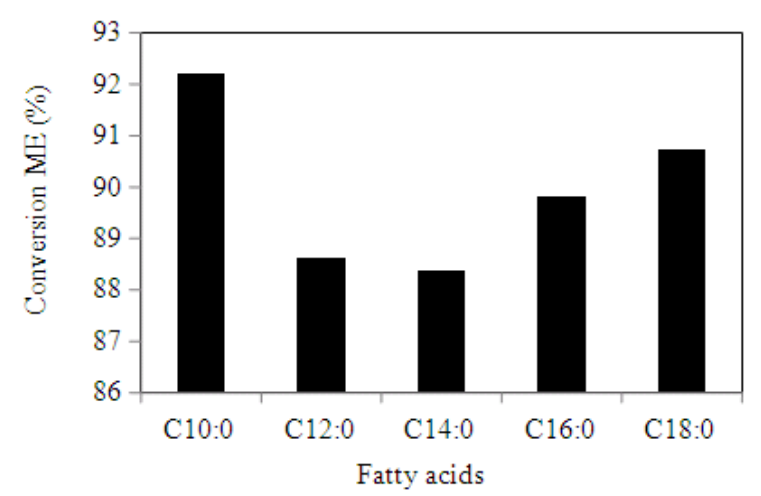

Fig. 6: Effects of chain lengths of saturated fatty acid and DMC. Time, $8 \mathrm{~h}$; temperature, $60^{\circ} \mathrm{C}$; catalyst, $10 \% \mathrm{wt}$

Effect of water: The amount of water in the reaction system is one of the critical factors that may affect the reaction product. As for the transesterification of palm kernel oil with dialkyl carbonate, sufficient amount of water is needed to promote lipase activity. In this study, the yield was increased up to more than $70 \%$ when water was added up to $0.2 \%$. However, percentage of yield start to decrease when more than $0.5 \%$ water was added (Fig. 5).

Effects of fatty acid chain length: Esterification of fatty acid with dialkyl carbonates was performed in order to found its effect on the ester formation. As shown in Fig. 6 and 7, the reaction rate was increase with decreasing in the carbon chain length of fatty acid. The studies were also shows that reaction rate of saturated fatty acids was higher than unsaturated fatty acids. 


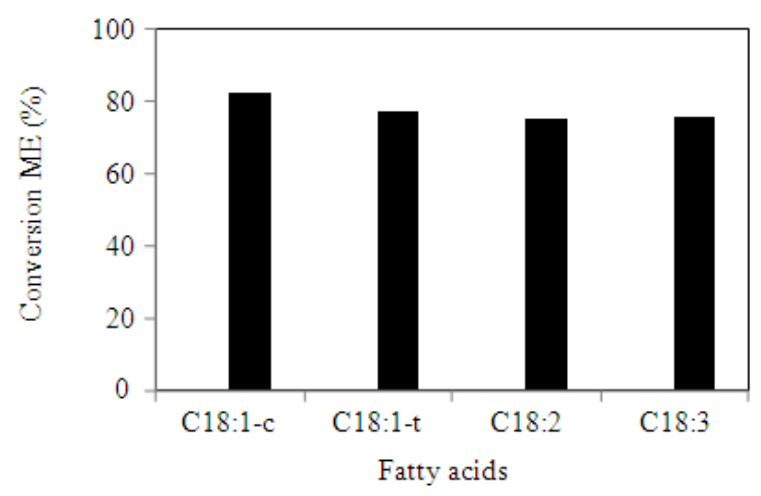

Fig. 7: Effects of chain lengths of unsaturated fatty acid and DMC. Temperature, $60^{\circ} \mathrm{C}$; time $8 \mathrm{~h}$; catalyst, $10 \% \mathrm{wt}$

Generally, lipase can be divided into five different groups; (a) substrate selectivity; (b) positionally selective (or regioselective); (c) non selective; (d) fatty acid selective (or acyl selective) and (e) stereoselective (or sn-glycerol specific). Candida sp. belongs to the class of triacylglycerol hydrolases (EC 3.1.1.3). It catalyses hydrolytic, esterification and transesterification reactions. It exhibits the same activity towards fatty acids in the range of $\mathrm{C}_{10}$ to $\mathrm{C}_{24}$ but it has a slightly higher activity towards fatty acid with shorter chains.

\section{CONCLUSION}

Solvent free lipase-catalyzed transesterification of PKO and dialkyl carbonates gave higher conversion of ester compared to the reaction using short chain alcohol as an alkyl donors. However, due to the cost of the catalyst used, future research may focus on the transesterification of PKO and dialkyl carbonate using chemical catalyst.

\section{REFERENCES}

Athawale, V., N. Manjrekar and M. Athawale, 2003. Effect of reaction parameter on synthesis of citronellyl methacrylate by lipase-catalyzed transesterification. Biotechnol. Prog., 19: 298-302. PMID: 12675563

Gryglewicz, S., F.A. Oko and G. Gryglewicz, 2003. Synthesis of modern synthetic oils based on dialkyl carbonates. Ind. Eng. Chem. Res., 42: 5007-5010. DOI: $10.1021 / \mathrm{ie} 030322 \mathrm{~m}$

Ono, Y., 1997. Dimethyl carbonate for environmentally benign reactions. Catal. Today, 35: 15-25. DOI: 10.1016/s0920-5861(96)00130-7

Pioch, D., P. Lozano and J. Graille, 1991. First lipasecatalyzed synthesis of fatty carbonates ester. Biotechnol. Lett., 13: 633-636. DOI: 10.1007/BF01086317

Shaikh, A. and S. Sivaran, 1996. Organic carbonates. Chem. Rev., 96: 951-976. DOI: 10.1021/cr950067i

Warwel, S., M.R.G. Klaas and R. Grothey, 1999a. Lipase catalyzed conversions with diethyl and dimethyl carbonate in oleochemistry. Proceeding of the 6th Symposium on Renewable Resources for the Chemical Industry, Mar. 23-25, Landwirtschafts Verlag, Munster, Bonn-Germany, pp: 93-105.

Warwel, S., R. Borgdorf and L. Bruhl, 1999b. Substrate selectivity of lipase in the esterification of oleic acid, linoleic acid, linolenic acid and their all-transisomers in the transesterification of cis/transisomers of linoleic acid methyl ester. Biotechnol. Lett., $\quad 21$ : 431-436. 10.1023/A:1005589028648 